\title{
Peripheral nerve biopsies in the diagnosis of leprosy in Aboriginal patients from the Northern Territory of Australia
}

\author{
A. C. M c D O U G A L L, D. J . H A R M N , H . W A U D Y Y, \\ A N D J. C. H A R G R A V E \\ From the Slade Hospital, Oxford, the Leprosy Study Centre, London, \\ and the East Arm Leprosy Hospital, Darwin, Australia
}

SUMMARY In the 12 years from 1964 to 1976, 171 peripheral nerve biopsies were taken from 81 Aboriginal patients in the Northern Territory of Australia, in whom a diagnosis of leprosy $\vec{\omega}$ was either known or strongly suspected. Sixty-eight biopsy samples were from 19 patients known to have leprosy, and who were under assessment for nerve grafting, results of which have $\overrightarrow{5}$ already been published. We describe here the histopathological findings in the remaining 62 i patients, in whom a diagnosis of leprosy was suspected on clinical grounds, backed in many cases by abnormalities of nerve conduction. Forty-one patients $(66 \%)$ had abnormal histopath logical findings in the nerve biopsy sample, $19(31 \%)$ showing definite evidence of lepros Several patients with enlarged peripheral nerves, in whom the biopsy findings did not confirie 을 leprosy, remain under observation; their future investigation will include lymphocyte transform路 $\overrightarrow{-}$ tion tests and testing with refined lepromin, together with repeat nerve biopsy, where ethic and feasible. The clinical and epidemiological data suggest that a previous, and perhaps self healing, form of leprosy may account for the neurological findings.

There are very few diseases in which the pathogen directly invades nerve and, among the mycobacteria, the leprosy bacillus is unique in this respect. Because of the delicate structure of endoneurial and perineurial tissues and their confinement within a relatively unyielding epineurial sheath, the consequences of bacillary invasion and cell response may be serious and longlasting for the patient. The clinical effects of this, and the histopathological changes have been described in full (Browne 1975; Weddell and Pearson, 1975), and nerve enlargement as a clinical sign has been carefully reviewed in relation to the classification of leprosy (Furness and Ranney, 1971). In a description of patients from different parts of the leprosy spectrum, Antia (1976) has shown that the qualitative involvement and quantitative bacillary load is higher in nerves than it is in skin, dartos, lymph node, nasal mucosa, or muscle. The

Address for reprint requests. Dr A C. McDougall, Department of Dermatology, The Slade Hospical, Headington, Oxford OX3 7JH. Accepted 25 May 1978 precise mode of transmission of leprosy-particularly as regards the portal of entry of the bacillus -is still unknown, as is the spread of the infection in the body between skin, nerve, and various other tissues, once entry has been achieved. While the $\frac{\circ}{\mathbb{Q}}$ skin lesions of leprosy are accompanied almost invariably by clinical or histopathological abnor- $\overrightarrow{\hat{O}}$ malities in nerve, the converse-namely, the finding of a neurological abnormality without present or past evidence of a visible skin lesion-is unusual although it occurs. Thus Cochrane and Davey (1964) state "neuritic leprosy is a relatively un-? common condition, but it has been described $\frac{0}{3}$ sufficiently frequently to give it an established place as a clinical entity." Occasional cases have $\frac{0}{3}$ been described in detail (Hargrave and Marion, $₹$ 1964; Jopling and Morgan-Hughes, 1965; Job et al., 음 1977), and in a recent study of over 11000 patients $D$ attending a clinic in India, Dongre et al. (1976) found evidence of primary polyneuritic leprosy in $N$ $4.3 \%$.

In the Northern Territory of Australia, where $N$ leprosy is endemic, it has been recorded (McLeod $N_{\omega}$ 
et al., 1975a) that a significant number of Aboriginal patients have neurological abnormalities, especially nerve enlargement, without evidence of leprosy in the skin. In the present paper we report the histopathological findings in nerve biopsies from 62 of these patients, most of whom had no skin lesion, and discuss the value, and limitations, of peripheral nerve biopsy in establishing the diagnosis of leprosy at this stage of the endemic.

\section{Patients and methods}

In the 12 years from 1964 to 1976,171 nerve biopsy specimens were taken from 81 Aboriginal patients in the Northern Territory and submitted to the Leprosy Study Centre in London for histopathological diagnosis and classification. These included 68 biopsy samples taken during course of assessment of 19 patients for surgical nerve grafting, results of which have already been published (McLeod et al., 1975b). The remaining 62 patients included 46 males and 16 females. Their ages ranged from 6 to 67 years with an average of 32 years. The females were mostly engaged in domestic work, and the males in tribal hunting and gathering activities, or cattle herding, often on horseback. The racial origins, recent history and development, and tribal customs of these people have been described in detail (Hargrave, 1975 ) in relation to the entry and spread of leprosy in the Northern Territory.

\section{CLINICAL EXAMINATION}

The neurological abnormalities described below were discovered during the course of routine examinations of large numbers of contacts of known leprosy patients in the Arnhem Land, Darwin, and North West Kimberley districts, or on limited surveys of small, often isolated, communities, some of them nomadic. With the exception of eight patients, there were no skin lesions to suggest leprosy, and the most important abnormality in the majority of patients was the enlargement of peripheral nerve or nerves, with impairment of nerve conduction. The nerves affected clinically included the ulnar, lateral popliteal, posterior tibial, sural, musculocutaneous nerves of the leg, and the supraclavicular, great auricular, and medial cutaneous nerves of the forearm. There was no instance of bilateral symmetrical nerve involvement and, indeed, considerable emphasis was placed on the findings of unilateral, asymmetrical enlargement as a criterion of abnormality before biopsy. Several of the nerves biopsied were not only palpably, but also visibly enlarged, a finding which was probably accentu- ated by the generally thin state of most Aboriginal patients at the time of this study. In 11 cases there was no definite nerve enlargement, but the physical signs included clawhand, dropfoot, or muscle wasting in one or more groups supplied by ulnar, median, lateral popliteal, or posterior tibial nerves.

\section{NERVE BIOPSY}

In a few cases where the enlarged nerve was superficial and easily palpable or visible, a limited incision was made under local anaesthesia. In most cases, and in all those involving a major peripheral nerve, the biopsy was taken as part of a full surgical exploration under general anaesthesia, usually in the operating theatre of the base hospital. Incisions in these cases were up to $16 \mathrm{~cm}$ in length, exposing the full extent of the nerve considered to be clinically abnormal. During the 12 years, and including a number of patients in whom the diagnosis remained in doubt, more than one nerve biopsy was often taken-thus 19 patients had two, and three had three biopsies.

\section{SKIN BIOPSY}

As already noted, only eight patients in this series had skin lesions. Biopsy samples were taken from macular, hypopigmented, or hypoaesthetic areas under local anaesthesia, using a small-bladed scalpel to obtain an ellipse of skin approximately $10 \mathrm{~mm} \times 4 \mathrm{~mm}$. Fixation of nerve and skin was in a modification of formol-Zenker, with transfer to $70 \%$ alcohol $15-24$ hours later, and staining was with a combined trichome and Fite-Faraco modification of Ziehl-Neelsen stain: TRIFF (Wheeler et al., 1965). Selected tissues were stained with congo red for examination for amyloid and were also examined under polarised light. Tissues were embedded in paraffin and cut (longitudinally and transversely in the case of nerve) at $5 \mu \mathrm{m}$.

ELECTROPHYSIOLOGY: NERVE CONDUCTION STUDIES Motor and sensory conduction velocities and mixed nerve action potentials were recorded as already described in previous studies (McLeod et al., 1975a, b). In the conventional apparatus installed at the East Arm Leprosy Hospital, the recording electrodes were connected to a Tektronix FM 122 preamplifier and displayed on the upper beam of a Tektronix 564 oscilloscope. The stimulus was an electric square wave of 0.2 $1.0 \mathrm{~ms}$ duration, and of up to $500 \mathrm{~V}$ amplitude from a DISA Ministim. In addition, a portable DISA machine of similar specification was also available, enabling recordings to be made under field conditions. 


\section{Results}

The 62 patients in this series can be grouped according to the most significant positive finding on histopathological examination of their nerve samples as follows: (1) definite evidence of leprosy, (2) evidence suggestive but not diagnostic of leprosy, (3) abnormal, but (with the exception of one patient who had evidence of neurofibromatosis) non-specific findings, (4) normal, and (5) inadequate or unsatisfactory material for examination.

\section{DEFINITE EVIDENCE OF LEPROSY}

There were 19 patients in this group and, with the two exceptions, the nerve biopsied was also the nerve affected clinically. Using the five group classification according to immunity (Ridley and Jopling, 1966), the biopsy specimens were classified-tuberculoid (TT) four; borderlinetuberculoid (BT) seven; borderline (BB) three; and borderline-lepromatous seven. One was unclassifiable on the material submitted. There was no instance of lepromatous (LL) leprosy in this group or indeed in the entire series. A surprising revelation was that of abscess formation (Figs. 14) in six patients, four of whom had no skin lesions; the other two did have skin lesions and a biopsy confirmed BT leprosy in one, and TT in the other. Details of these patients are shown in the Table.

\section{EVIDENCE SUGGESTIVE BUT NOT DIAGNOSTIC OF LEPROSY}

Seven patients had biopsy samples which were negative for bacilli or bacillary remnants but showed a round cell infiltration, together with disruption of normal endoneurial and perineurial structure, suggestive, but not absolutely diagnostic of leprosy. Some histiocytes showed epithelioid change, and in one or two instances there were a few Langhans or foreign body giant cells in the

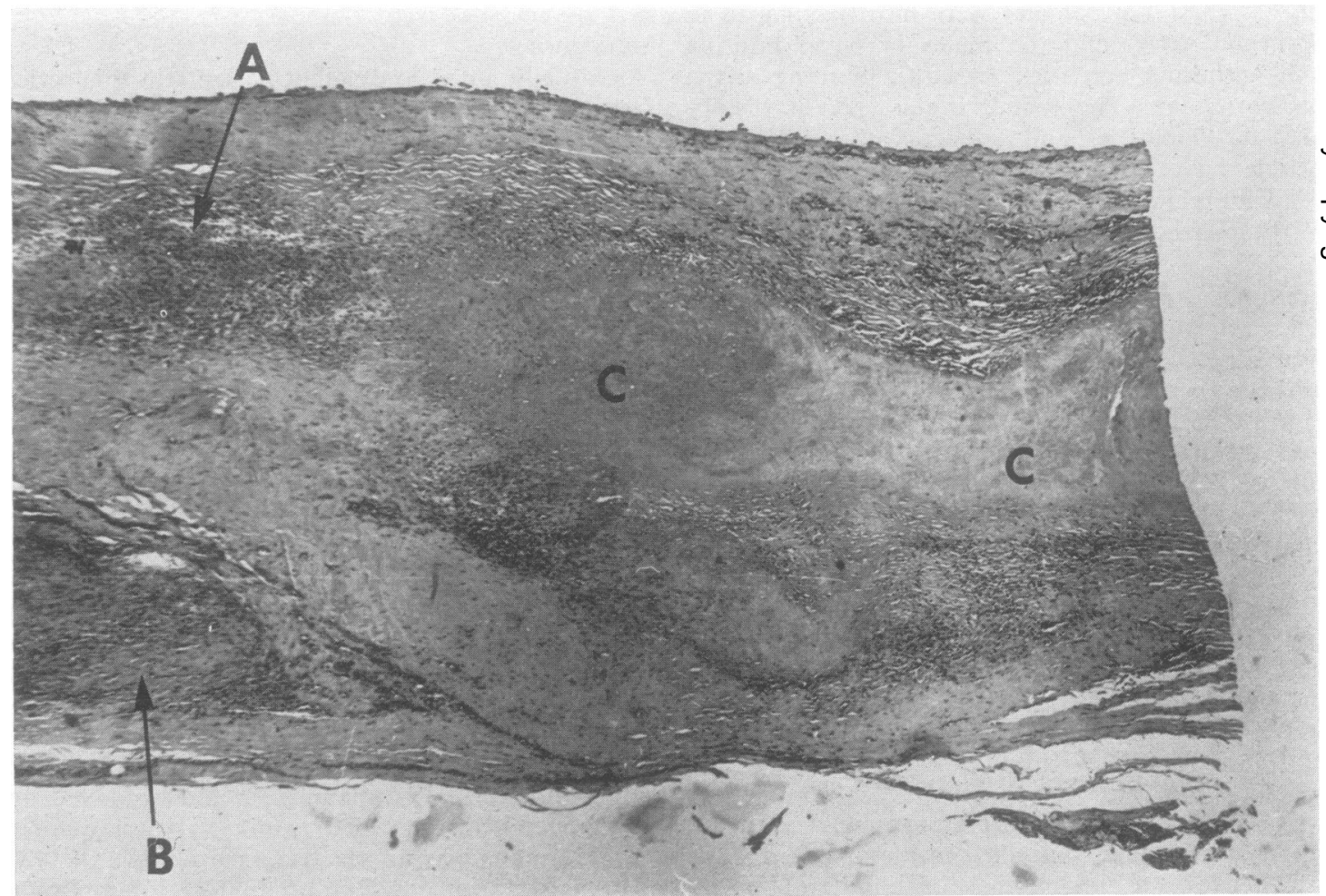

Fig. 1 Patient 6. Musculocutaneous nerve of the leg: longitudinal section. Fascicles at $A$ and $B$ showed intense cellular infiltration with histiocytes and lymphocytes. There is abscess formation at $C$, which, on the right side, clearly extends beyond the limit of the tissue biopsied. No acid-fast bacilli were found. TRIFF stain. Original magnification $\times 40$. 


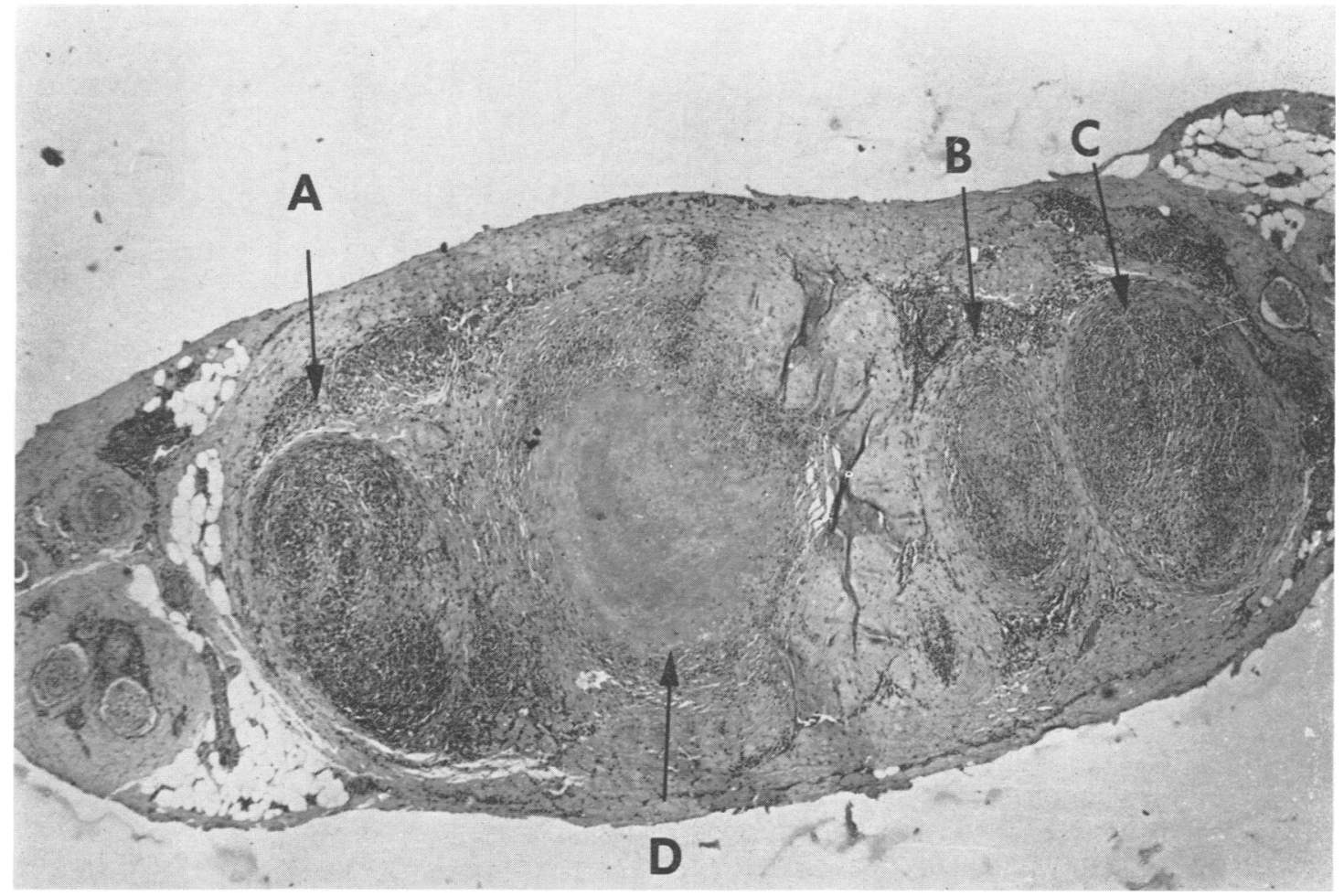

Fig. 2 The same patient and nerve, cross-section. Fascicles at $A, B$, and $C$ are heavily infiltrated, while that at $D$ shows abscess formation. No acid-fast bacilli found. TRIFF stain. Original magnification $\times 40$.

affected areas. Amyloid (congo red and polarised light examination) was not found around vessels, or elsewhere, in any of these specimens.

\section{ABNORMAL BUT NON-SPECIFIC FINDINGS}

The 14 biopsy specimens in this group showed histiocytic or lymphocytic infiltration of slight degree in a few instances, but the striking finding was collagenisation, affecting endoneurial and perineurial areas, and often marked in degree. Schwann cells and myelin in these areas were reduced or absent. Amyloid was not present. The biopsy specimen of one patient showed neurofibromatosis.

\section{NORMAL FINDINGS}

Fourteen patients (18 biopsies) had completely normal findings on histopathological examination, despite the fact that all were taken in the operating theatre, often from nerves which were visibly enlarged, and that most patients in this group also had abnormal nerve conduction findings. Taken with the clinical findings, these data have led to the diagnosis and registration of six of these patients as suffering from leprosy, despite the negative biopsy.

\section{INADEQUATE OR UNSATISFACTORY}

\section{MATERIAL}

In seven patients, the material submitted consisted of fat, connective tissue or blood vessel wall (the latter in three instances), and no neural tissue was found. Blood vessel walls were examined and found negative for bacilli or infiltrate.

In the five groups described above, there was a discrepancy in 12 instances $(28 \%)$ between the nerve affected clinically and the nerve actually biopsied, but in three of these the biopsy was taken from a closely adjacent small branch supplying a neighbouring joint or muscle. In the remaining nine, the most common discrepancy was biopsy of the radial nerve at the wrist instead of the ulnar nerve at the elbow, and the second most common was biopsy of the superficial peroneal instead of the lateral popliteal nerve. The significance of this, with particular regard to the overall percentage of non-confirmatory biopsies for leprosy, is discussed below. 


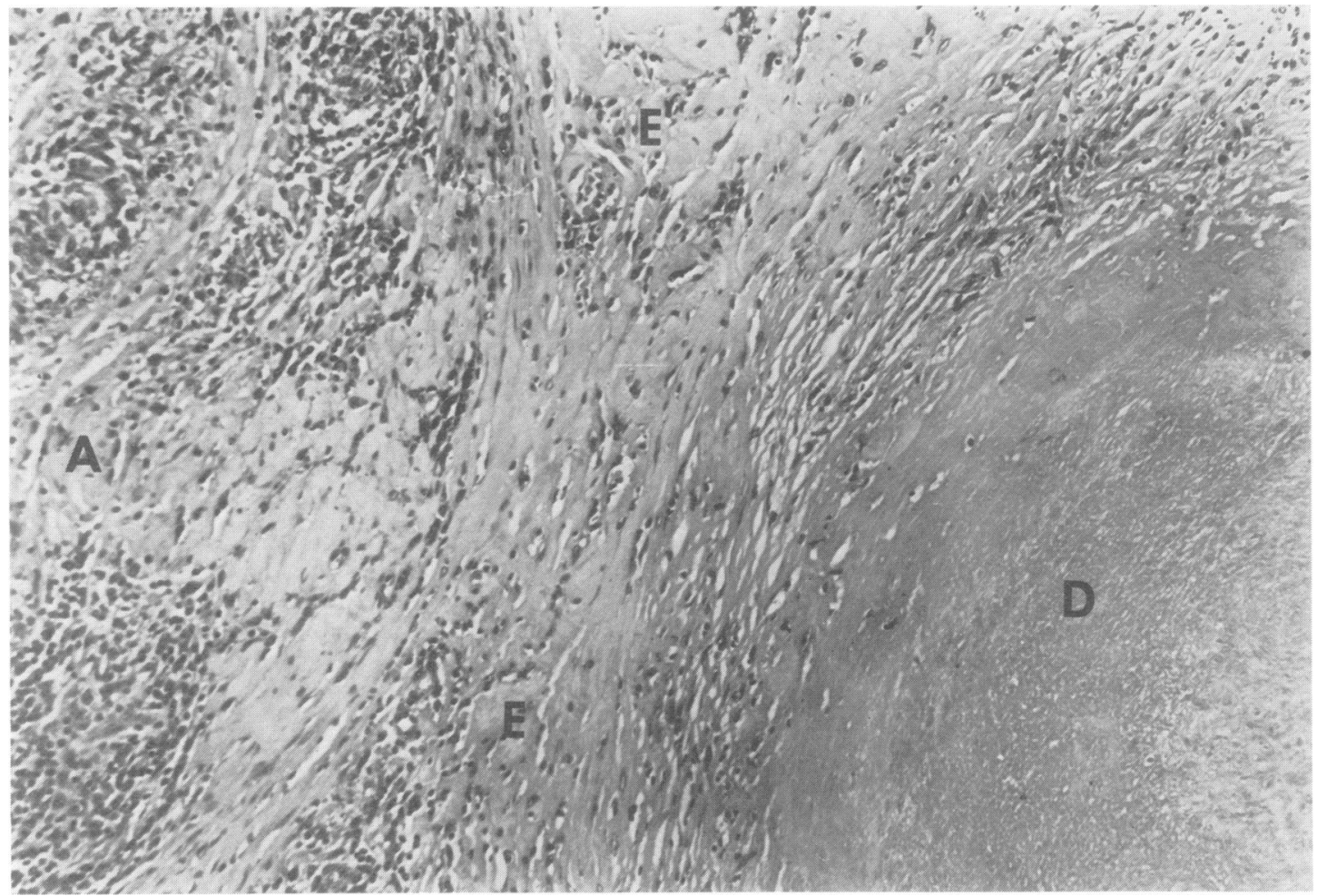

Fig. 3 Fascicles $A$ and $D$, as in Fig. 2, are shown here at higher magnification. A, on the left, intensely infiltrated and $D$, on the right, with abscess formation. $E=$ epineurial collagen. TRIFF stain. Original magnification $\times 160$.

Nerve conduction studies were carried out in 44 out of the total of 62 patients. Thirty had definite abnormalities in conduction velocities or in the amplitude of mixed nerve action potentials or both, based on criteria already established and taking into account the known range of normal in control subjects in this community (McLeod et al., 1975a). These abnormalities were interpreted as corroborative evidence of peripheral neuropathy-or of leprosy-if associated with one or more of the factors described below.

All 19 patients with confirmatory nerve biopsies were treated with dapsone by mouth and most of them are still taking this, with or without other antileprosy drugs, at the time of writing. Of the other 43 patients, of whom 21 had abnormal histopathological but not diagnostic findings, 28 were in fact eventually registered and treated as having leprosy for one or more of the following reasons: (1) the clinical findings were suggestivethese included nerve enlargement, plus muscle paralysis, skin anaesthesia, and chronic ulceration, separately or in combination; (2) nerve con- duction studies were abnormal; (3) there were close relatives with leprosy; (4) careful inspection of the nerve at operation confirmed that it was abnormal.

One of the remaining 15 patients showed neurofibromatosis in the biopsy sample but had no clinical or other evidence of leprosy. There are, therefore, 14 who have not been registered or treated and who remain under close observation. Ten of them have a clinically enlarged nerve or nerves for which no explanation has been found.

\section{Discussion}

The precise presentation of these data is complex because of the 12 years during which many of the patients were under observation, together with the fact that several of them had more than one biopsy. The main facts are, however, clear. From the total of 62 patients with abnormal neurological findings in the nerve biopsy samples, $19(31 \%)$ showed definite evidence of leprosy. In accounting for the rather low proportion of positive 


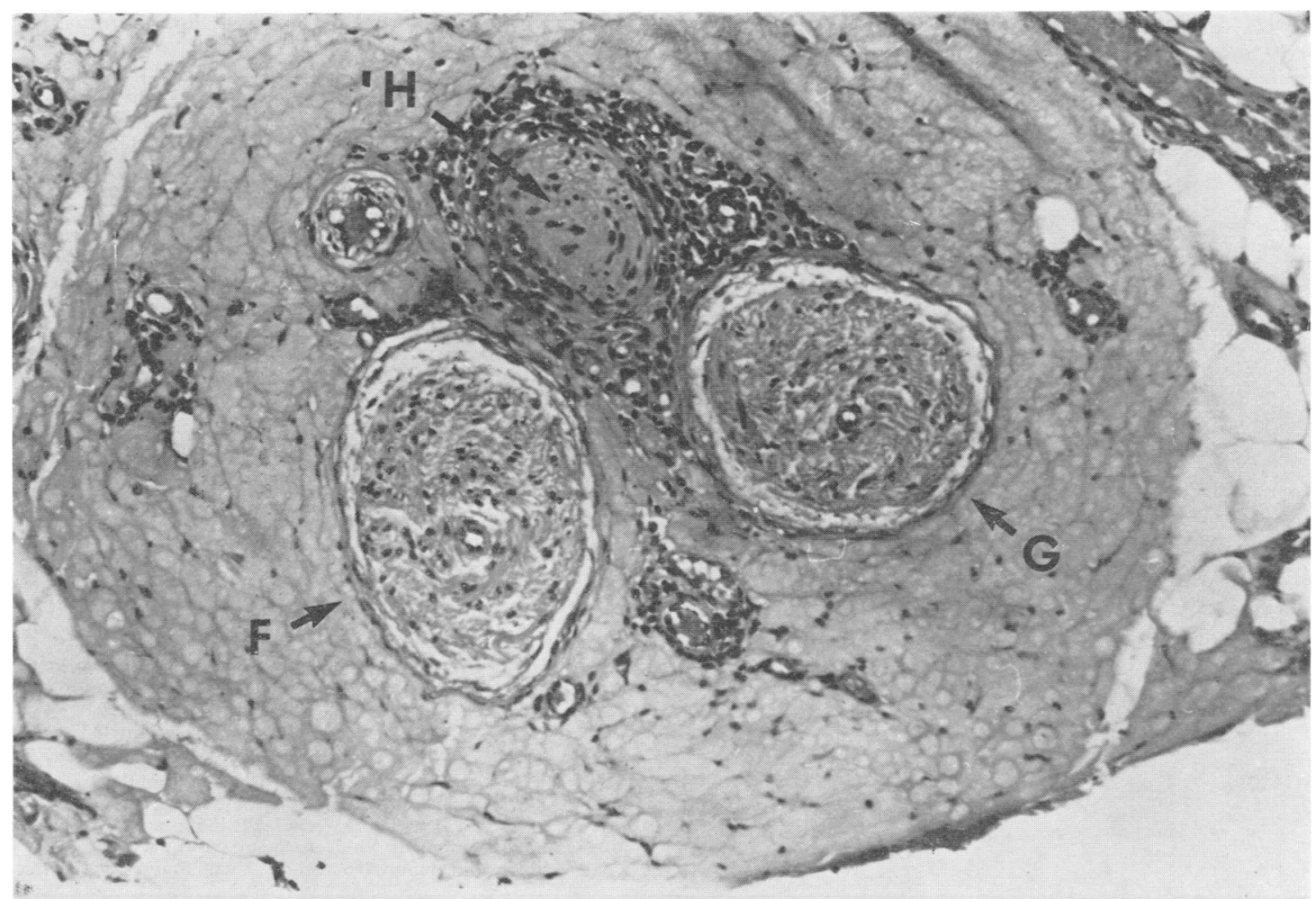

Fig. 4 From the extreme left of Fig. 2, two completely normal fascicles, $F$ and $G$, are shown adjacent to another, at $H$, which has a few infiltrating cells in the endoneurial area, and many more in and around its perineurium. TRIFF stain. Original magnification $\times 160$.

confirmation by biopsy in patients clinically suspected of having leprosy, we thought initially that there would be many instances of discrepancy between the nerve affected clinically and the nerve actually biopsied, because of reluctance on the part of the operator to biopsy a major peripheral nerve or to the taking of a small branch to a neighbouring joint or muscle. But this occurred in only 12 instances, less than one-third of all those in whom the biopsy was not diagnostic of leprosy. In retrospect, we conclude that most of those in the latter category, together with the seven in which the material was not adequate for examination, were the result of the ethical limitations of incising a major peripheral nerve, even when fully exposed, and seen to be abnormal, at operation. Two other factors may be relevant. Firstly, the biopsy material in some instances, particularly in the earlier years, may have been taken too superficially, or from either normal epineurium or post-inflammatory or posttraumatic fibrous tissue. Secondly, even with a deep enough incision, normal fasciles may have been biopsied, since it is a matter of common knowledge, especially if transverse sections from many nerve biopsy samples are examined, that normal and pathological fascicles may lie side by side in nerves affected by leprosy (Fig. 4). We hope to minimise these errors in future by the use of +1 diopter lenses on a forehead attachment, or the operating microscope in selected cases.

In the 19 patients with definite evidence of leprosy in the nerve biopsy (group 1), the occurrence of abscess formation in no fewer than six $(32 \%)$ was surprising, and unsuspected clinically. Furthermore, it was extensive in most of them, and obviously beyond the limits of the tissue biopsied in three (Fig. 1). Caseation is far from common in leprosy and occurs mainly in the centres of nerves, usually in the fascicles of nerve trunks, but occasionally in dermal nerves. It is a manifestation of hypersensitivity, most commonly occurring in, and often helping to define, the tuberculoid (TT) group (Ridley, 1974), though in the small group described here, the histopathological findings in nerve suggested borderline 
Table Six patients with abscess formation in the nerve biopsy; nerve affected, classification, and salient histopathological findings

\begin{tabular}{|c|c|c|c|c|c|}
\hline Number & $\operatorname{Sex}$ & $\begin{array}{l}\text { Age } \\
(y r)\end{array}$ & Nerve clinically affected ${ }^{*}$ & Classification & Histopathological findings \\
\hline $1(7291)$ & $\mathbf{M}$ & 11 & Supraclavicular & TT & $\begin{array}{l}\text { Gross cellular infiltration of endo- and perineurial zones } \\
\text { with histiocytes and lymphocytes, the former showing } \\
\text { epitheloid change and focalisation. Many giant cell } \\
\text { formations. Extensive tissue breakdown in many parts of } \\
\text { the biopsy with almost complete destruction of all neural } \\
\text { tissue. No acid-fast bacilli found. }\end{array}$ \\
\hline $2(7685)$ & $\mathbf{M}$ & 20 & Anterior cutaneous of neck & $\begin{array}{l}\text { BT } \\
\text { (upgrading } \\
\text { from BB) }\end{array}$ & $\begin{array}{l}\text { Gross cellular infiltrate (histiocytes, lymphocytes, and } \\
\text { plasma cells) which has distorted and destroyed most of } \\
\text { the nerve fibres. Several areas of tissue breakdown (abscess } \\
\text { formation) throughout the nerve. No acid-fast bacilli } \\
\text { found. }\end{array}$ \\
\hline $3(7874)$ & $\mathbf{M}$ & 17 & Medial cutaneous of forearm & TT & $\begin{array}{l}\text { Gross cellular infiltration (histiocytes, lymphocytes, and } \\
\text { plasma cells) with resultant necrosis and abscess formation. } \\
\text { A few giant cell formations. Occasional remnants of acid-fast } \\
\text { bacilli in endoneurial and perineurial zones. }\end{array}$ \\
\hline $4(9551)$ & $\mathbf{M}$ & 11 & Musculocutaneous of leg & BT & $\begin{array}{l}\text { Marked thickening of the perineurial tissues, with } \\
\text { infiltration by histiocytes, lymphocytes, and plasma cells. } \\
\text { Similar infiltration, marked in degree, of endoneurial zone, } \\
\text { with tissue necrosis, abscess formation, and occasional } \\
\text { acid-fast remnants. }\end{array}$ \\
\hline $5(9823)$ & $\mathbf{M}$ & 16 & Ulnar & BB & $\begin{array}{l}\text { Gross infiltration of main zones with histiocytes, } \\
\text { lymphocytes, and plasma cells, some histiocytes showing } \\
\text { epithelioid change. Considerable necrosis of endoneurial } \\
\text { tissue. Acid-fast bacilli in remnants scattered throughout, } \\
\text { but also occasional forms which are solid-staining (and } \\
\text { may, therefore, be viable). }\end{array}$ \\
\hline $6(14535)$ & $\mathbf{F}$ & 25 & Musculocutaneous of leg & $\begin{array}{l}\text { BT } \\
\text { (upgrading } \\
\text { from BB) }\end{array}$ & $\begin{array}{l}\text { Exceptionally revealing tissue, with nine bundles in } \\
\text { longitudinal and cross-section, some completely normal, } \\
\text { but others (the majority) markedly infiltrated by histiocytes } \\
\text { and lymphocytes, with consequent tissue necrosis and } \\
\text { abscess formation. No acid-fast bacilli found (Figs. 1-4). }\end{array}$ \\
\hline
\end{tabular}

*In this group of patients (but not in others-see text), the nerve biopsied was in all six cases the same as the nerve affected clinically.

(BB) and borderline-tuberculoid (BT) in three (Table). Apart from the element of hypersensitivity noted above, the findings in two cases also pointed to reversal (upgrading) reaction (Ridley, 1969), with a marked influx of inflammatory cells which may have contributed to ischaemia and necrosis.

In the seven patients of group 2, where the histopathological findings were suggestive but not diagnostic of leprosy, all but one have in fact been diagnosed as leprosy, for one or more of the reasons given above. A retrospective examination of the biopsy specimens does not suggest any reasonable alternative diagnosis.

In the group of 14 patients with non-specific abnormalities in the nerve biopsy, mainly collagenisation, there were three with diabetes mellitus, and six whose daily intake of alcohol was unusually high. Alcoholism, malnutrition, trauma, diabetes mellitus are clearly factors that must be considered in those patients for whom there is, as yet, no definite proof of leprosy. While acknowledging that there is still an area of uncertainty about the significance of clinically enlarged nerves in some populations (CIBA Foundation Study
Group, 1963), it is generally agreed that the above factors do not explain clinical nerve enlargement. Its occurrence, confirmed by experienced observers, in this leprosy-endemic area, often in a patient with one or more family members affected with leprosy, emphasises the need to keep this diagnosis in mind and to pursue it by other means. Furthermore, the histopathological finding of collagenisation is entirely compatible with "the endstage of a leprosy lesion in nerve" (Job et al., 1977).

Not only for this group of patients, but also in order to study the slow but definite spread of leprosy in the Northern Territory to the South, and into the desert tribes (Hargrave, 1975), we now consider that the lymphocyte transformation test (Bullock and Fasal, 1971; Godal et al., 1971) should be applied to apparently healthy contacts and others in whom infection, clinical or subclinical, is suspected. This, combined with repeat nerve biopsy, where ethical and feasible, and possibly skin testing with refined lepromin at a later date, should help in the further investigation of certain nerve lesions (as yet undiagnosed) in these Aboriginal patients, with particular reference to 
the possibility that they represent a previous, and perhaps self-healing, form of leprosy.

We are grateful to the Director of the Leprosy Study Centre, Dr S. G. Browne, for permission to refer to the clinical records and histopathological reports of patients in this paper, to Dr A. Dyrting, Superintendent of the East Arm Leprosy Hospital, who performed many of the biopsies, and to Sister Annette Barron who carried out most of the nerve conduction studies. A. C. McDougall is supported by the British Leprosy Relief Association (LEPRA) and by a grant from the Oxfordshire Area Health Authority (Teaching).

\section{References}

Antia, N. H. (1976). Qualitative histology and quantitative bacteriology in various tissues of 50 leprosy patients. Leprosy Review, 47, 175-183.

Browne, S. G. (1975). Leprosy-clinical aspects of nerve involvement. In Topics on Tropical Neurology. Edited by R. W. Hornabrook. F. A. Davis Company: Philadelphia.

Bullock, W. E., Jr., and Fasal, J. (1971). Studies of immune mechanisms in leprosy. Journal of Immunology, 106, 888-899.

CIBA Foundation Study Group No. 15 (1963). Pathogenesis of Leprosy. J. and A. Churchill Ltd: London.

Cochrane, R. G., and Davey, T. F. (1964). Leprosy in Theory and Practice. John Wright and Sons: Bristol.

Dongre, V. V., Ganapati, R., and Chulawala, R. G. (1976). A study of mono-neuritic lesions in a leprosy clinic. Leprosy in India, 48, 132-137.

Furness, M. A., and Ranney, D. A. (1971). Nerve enlargement in relation to classification of leprosy. Leprosy Review, 2, 208-218.

Godal, T., Myklestad, B., Samuel, D. R., and Myrvang, B. (1971). Characterisation of the cellular immune defect in lepromatous leprosy: a specific lack of circulating Mycobacterium leprae reactive lymphocytes. Clinical and Experimental Immunology, 9, 821-831.

Hargrave, J. C., and Marion, Rev. Mother. (1964). Leprotic involvement of multiple peripheral nerves in the absence of skin lesions. Leprosy Review, 35, 78-82.

Hargrave, J. C. (1975). Leprosy in the Northern Territory of Australia with particular reference to the Aboriginals of Arnhem Land and the arid regions of the Northern Territory. Thesis submitted to University of Sydney for degree of Doctor of Medicine.

Job, C. K., Victor, D. B. I., and Chacko, C. J. G. (1977). Progressive nerve lesion in a diseasearrested leprosy patient. An electron microscope study. International Journal of Leprosy, 45, 255260.

Jopling, W. H., and Morgan-Hughes, J. A. (1965). Pure neural tuberculoid leprosy. British Medical Journal, 2, 799-800.

McLeod, J. G., Hargrave, J. C., Walsh, J. C., Booth, G. C., Gye, R. S., and Sister Annette Barron. (1975a). Nerve conduction studies in leprosy. International Journal of Leprosy, 43, 21-31.

McLeod, J. G., Hargrave, J. C., Gye, R. S., Pollard, J. D., Walsh, J. C., Little, J. M., and Booth, G. C. (1975b). Nerve grafting in leprosy. Brain, 98, 203212.

Ridley, D. S., and Jopling, W. H. (1966). Classification of leprosy according to immunity. A fivegroup system. International Journal of Leprosy, 34, 255-273.

Ridley, D. S. (1969). Reactions in leprosy. Leprosy Review, 40, 77-81.

Ridley, D. S. (1974). Histological classification and the immunological spectrum of leprosy. Bulletin of the World Health Organisation, 51, 451-465.

Weddell, A. G. M., and Pearson, J. M. H. (1975). Leprosy-Histopathologic aspects of nerve involvement. In Topics on Tropical Neurology. Edited by R. W. Hornabrook. F. A. Davis Company: Philadelphia.

Wheeler, E. A., Hamilton, E. G., and Harman, D. J. (1965). An improved technique for the histopathological diagnosis and classification of leprosy. Leprosy Review, 36, 37-39. 